\title{
Environmental Control and Life Support (ECLS) Hardware Commonality for Exploration Vehicles
}

\author{
Robyn L. Carrasquillo ${ }^{1}$ \\ NASA Marshall Space Flight Center, Huntsville, AL, 35812 \\ Molly Anderson ${ }^{2}$ \\ NASA Johnson Space Center, Houston, Texas, 77062, USA
}

\begin{abstract}
In August 2011, the Environmental Control and Life Support Systems (ECLSS) technical community, along with associated stakeholders, held a workshop to review NASA's plans for Exploration missions and vehicles with two objectives: revisit the Exploration Atmospheres Working Group (EAWG) findings from 2006, and discuss preliminary ECLSS architecture concepts and technology choices for Exploration vehicles, identifying areas for potential common hardware or technologies to be utilized. Key considerations for selection of vehicle design total pressure and percent oxygen include operational concepts for extravehicular activity (EVA) and prebreathe protocols, materials flammability, and controllability within pressure and oxygen ranges. New data for these areas since the 2006 study were presented and discussed, and the community reached consensus on conclusions and recommendations for target design pressures for each Exploration vehicle concept. For the commonality study, the workshop identified many areas of potential commonality across the Exploration vehicles as well as with heritage International Space Station (ISS) and Shuttle hardware. Of the 36 ECLSS functions reviewed, 16 were considered to have strong potential for commonality, 13 were considered to have some potential commonality, and 7 were considered to have limited potential for commonality due to unique requirements or lack of sufficient heritage hardware. These findings, which will be utilized in architecture studies and budget exercises going forward, are presented in detail.
\end{abstract}

\section{Nomenclature}

$\begin{array}{ll}\mathrm{CO} & =\text { Carbon Monoxide } \\ \mathrm{CO}_{2} & =\text { Carbon Dioxide } \\ \mathrm{Psia} & =\text { pounds per square inch absolute } \\ \mathrm{HCl} & =\text { Hydrogen Chloride } \\ \mathrm{HCN} & =\text { Hydrogen Cyanide } \\ \mathrm{kPa} & =\text { kilopascals } \\ \mathrm{ppO}_{2} & =\text { partial pressure of oxygen } \\ \mathrm{O}_{2} & =\text { oxygen }\end{array}$

\section{Introduction}

$\mathrm{U}$ nder the current constrained budget environment, it is a considerable challenge for NASA to achieve exploration mission goals. One of the key challenges for missions beyond low Earth orbit and for long durations with minimal resupply is the design of the Environmental Control and Life Support System (ECLSS). While the International Space Station (ISS) has served to evolve the State of the Art (SoA) ECLSS to one which is able to regenerate water and partially regenerate oxygen, there are targeted improvements needed before such a system can be relied upon for long duration crewed missions in deep space. In the summer of 2011, in response to

${ }^{1}$ Orion Functional Area Manager for Crew Support and Thermal Systems, Space Systems Department, ECLSS Branch/ES62, NASA Marshall Space Flight Center, AIAA Member.

${ }^{2}$ Life Support Engineer, Mail Stop EC6, NASA Johnson Space Center, AIAA Member. 
requests from the NASA Human Exploration Operations Mission Directorate (HEOMD), the ECLSS community convened for the purpose of addressing the current ECLSS SoA and its deficiencies to be able to support future exploration missions, and to begin to develop a plan to address those deficiencies in the most cost-effective manner possible. A key step in this process was to identify, for each ECLSS function, where common components or subsystems could potentially be utilized across multiple elements of the exploration architecture. This activity was in direct response to a growing perception that element architecture teams were each conceiving of an entirely different, new ECLSS, and not considering commonality with either heritage Shuttle or ISS components, or commonality of new components across multiple elements. For the exploration architecture to ultimately be affordable, commonality is a mandatory consideration.

\section{Process and Data Collection}

Key participants in the workshop included representatives from all technical areas within the ECLSS community, representatives from major architecture element concept design teams, Space and Life Sciences/Crew Health, Materials and Processes, and Extravehicular Activity (EVA). A spreadsheet was utilized which included a breakdown of the various ECLSS functions and the expected types of exploration elements including the Multipurpose Crew Vehicle (MPCV), Multi-Mission Space Exploration Vehicle (MMSEV), Space Exploration Vehicle (SEV, also referred to as the Small Pressurized Rover (SPR) but is essentially a surface version of the MMSEV), Lander, a Deep Space Hab (DSH), and surface habitats. Suit Portable Life Support System (PLSS) components were also considered where relevant. Also included for reference were the Shuttle and International Space Station, as use of heritage equipment if possible is key to making future elements affordable. For each ECLSS function, the historical SoA was described, followed by the current thinking among the group as to what was being considered for each element to fulfill that function, whether an improvement or deviation from the SoA was warranted, and whether the solution could be common across multiple elements. Good consensus was reached during the 2-day workshop. Note that this product represented a point in time and architecture studies since then may alter the elements considered, and resulting recommendations. Figure 1 shows a small subset of the raw data collected in the spreadsheet.

\begin{tabular}{|c|c|c|c|c|c|c|c|c|c|}
\hline \begin{tabular}{|l|} 
Function/ \\
Component
\end{tabular} & Shuttle & ISS & MPCV (Orion) & Suits (PLSS) & SEV & MMSEV & Lander & DSH & Surface Hab \\
\hline $\begin{array}{l}\text { Atmosphere } \\
\text { Management }\end{array}$ & $\begin{array}{l}\text { note: for } \\
\text { rotating equip, } \\
\text { Shuttle used } \\
115 \mathrm{~V}, 3 \text {-phase }\end{array}$ & & & & & & & & \\
\hline \multicolumn{10}{|l|}{\begin{tabular}{|l|} 
Air \\
Revitalization
\end{tabular}} \\
\hline \multirow[t]{2}{*}{$\mathrm{CO} 2$ removal } & $\begin{array}{l}\text { LiOH; RCRS } \\
\text { (amine swing } \\
\text { bed) }\end{array}$ & $\begin{array}{l}\text { CDRA (zeolite, } \\
\text { water save); } \\
\text { ESA ACLS } \\
\text { steam } \\
\text { desorbed } \\
\text { amine } \\
\text { proposed flt } \\
\text { expt (water } \\
\text { save); Silver } \\
\text { Oxide (Airlock } \\
\text { EVA), Russian } \\
\text { Vozdukh } \\
\text { (amine, water } \\
\text { save). } \\
\end{array}$ & $\begin{array}{l}\text { amine PSA (CO2 } \\
\text { vented); } \\
\text { deployable } \mathrm{LiOH} \\
\text { for postlanding } \\
\text { (in } \\
\text { development) } \\
\end{array}$ & \begin{tabular}{|l} 
amine PSA \\
(smaller, \\
shorter cycles)
\end{tabular} & \begin{tabular}{|l|} 
MPCV or PLSS- \\
size PSA. \\
Must ensure \\
materials good \\
for 8 psi
\end{tabular} & \begin{tabular}{|l} 
\\
MPCV or PLSS- \\
size PSA. Must \\
ensure \\
materials good \\
for 8 psi
\end{tabular} & $\begin{array}{l}\text { same as } \\
\text { MPCV }\end{array}$ & $\begin{array}{l}\text { Improved ISS } \\
\text { CDRA with } \\
\text { robust } \\
\text { sorbent, } \\
\text { changes to up } \\
\text { front water } \\
\text { save, } \\
\text { compressor } \\
\text { for CO2 } \\
\text { recovery } \\
\text { (assumed as } \\
\text { LPCOR) }\end{array}$ & Same as DSH \\
\hline & $\begin{array}{l}\text { Issues: } \\
\text { stowage vol. }\end{array}$ & $\begin{array}{l}\text { Issues: zeolite } \\
\text { containment, } \\
\text { heater and } \\
\text { sensor failures }\end{array}$ & \multicolumn{7}{|c|}{$\begin{array}{l}\text { Possibility to use common amine or zeolite-based bed core (CARE concept) with/without upstream water removal } \\
\text { and } \mathrm{CO} 2 \text { recovery components depending on mission trades. Common bed allows reduced mission spares. } \\
\text { Design for } 8 \mathrm{psi} / 34 \% \mathrm{O} 2 \text {. }\end{array}$} \\
\hline Humidity control & $\mathrm{CHX} /$ spin sep & $\mathrm{CHX} /$ spin sep & $\begin{array}{l}\text { amine PSA } \\
\text { (H2O vented) }\end{array}$ & $\begin{array}{l}\text { amine PSA } \\
\text { (smaller, } \\
\text { shorter cycles) } \\
\end{array}$ & \begin{tabular}{|l|} 
MPCV or PLSS- \\
size PSA. \\
Must ensure \\
materials good \\
for 8 psi \\
\end{tabular} & $\begin{array}{l}\text { MPCV or PLSS- } \\
\text { size PSA. Must } \\
\text { ensure } \\
\text { materials good } \\
\text { for } 8 \text { psi } \\
\end{array}$ & $\begin{array}{l}\text { same as } \\
\text { MPCV }\end{array}$ & $\mathrm{CHX} /$ spin sep & $\begin{array}{l}\mathrm{CHX}+\text { partial- } \\
\text { g sep }\end{array}$ \\
\hline & & & $\begin{array}{l}\text { May trade water } \\
\text { save for MPCV } \\
\text { evolution }\end{array}$ & \multicolumn{4}{|c|}{ Possibililty for common PSA beds for open-loop applications } & $\begin{array}{l}\text { Common with } \\
\text { ISS or ISS } \\
\text { technology }\end{array}$ & \\
\hline
\end{tabular}

Figure 1. Sample commonality data collection spreadsheet 
One key factor which influences the hardware choices for the various exploration elements is the atmosphere pressure and percent oxygen assumed. For this reason the workshop participants first spent a day reviewing the work of the Exploration Atmospheres Working Group (EAWG) from $2006^{1}$. The intent was not to redo what took the EAWG a year and a half to complete, but to determine if factors affecting the EAWG recommendations had changed since that time. Those factors include material flammability data, prebreathe protocols and assumptions regarding frequent EVA's for exploration missions, the ability of the ECLSS to tightly control total cabin pressure and partial pressure of oxygen $\left(\mathrm{ppO}_{2}\right)$, and any updates to the lower $\mathrm{ppO}_{2}$ limit from a medical perspective. The original EAWG had recommended that future vehicles be designed for a $55.2 \mathrm{kPa}(8 \mathrm{psia}) / 32 \% \mathrm{O}_{2}$ environment; however, it also recognized that additional materials flammability testing would be required along with validation of prebreathe protocols and acclimatization times. The EAWG made an exception for the MPCV, because it was already being designed around Shuttle heritage for $70.3 \mathrm{kPa}(10.2 \mathrm{psia})$ and $30 \% \mathrm{O}_{2}$, and the EAWG recommended no change be made. Though an entire paper can be devoted to this subject, after reviewing new material flammability findings, mission objectives, and considering cost constraints associated with recertification of heritage hardware, in summary the August workshop reached the following consensus:

- The MPCV design point should remain at $70.3 \mathrm{kPa}(10.2 \mathrm{psia})$ and $30 \% \mathrm{O}_{2}$ in order to not perturb ongoing design. While a change to $55.2 \mathrm{kPa}(8 \mathrm{psia}) / 32 \% \mathrm{O}_{2}$ would offer mission flexibility, it would likely require material changes that would result in weight impacts to an already weight-constrained vehicle (for example, composite materials and the windows would be marginal at higher $\% \mathrm{O}_{2}$. However, in the interest of commonality, we should investigate what the impact would be to certify specific hardware components to 55.2 $\mathrm{kPa}(8 \mathrm{psia}) / 32 \% \mathrm{O}_{2}$ that could be used across the architecture. For example, the atmosphere revitalization equipment contained in the MPCV "suit loop" is already being designed to operate in a $100 \% \mathrm{O}_{2}$ environment.

- For DSH, the advantage of designing to $55.2 \mathrm{kPa}$ (8 psia) for operational flexibility with an attached MMSEV is likely outweighed by the disadvantages of limiting use of heritage and commercial off the shelf (COTS) hardware. The group recommended that the DSH design point be $70.3 \mathrm{kPa}(10.2 \mathrm{psia}) / 30 \% \mathrm{O}_{2}$, but that common ISS hardware be assessed for impacts to certification to $55.2 \mathrm{kPa}(8 \mathrm{psia}) / 32 \% \mathrm{O}_{2}$.

- The MMSEV and SEV should be designed for both $70.3 \mathrm{kPa}(10.2 \mathrm{psia}) / 30 \% \mathrm{O}_{2}$ and $55.2 \mathrm{kPa}(8 \mathrm{psia}) / 32 \% \mathrm{O}_{2}$, with suitports at $55.2 \mathrm{kPa}(8 \mathrm{psia})$ and isolated from the $70.3 \mathrm{kPa}(10.2 \mathrm{psia})$ pressure. The ops con would have the MPCV, DSH, and MMSEV all at $70.3 \mathrm{kPa}$ (10.2 psia) during transit with hatches open, then prior to arriving at the destination, the crew would ingress the MMSEV, close the hatch to the DSH, and depressurize to $55.2 \mathrm{kPa}(8 \mathrm{psia})$ to allow acclimatization prior to EVA.

- For Landers, the previous recommended pressures/ops concept remains unchanged. The Lander should operate at $70.3 \mathrm{kPa}(10.2 \mathrm{psia})$ for transit/docked ops with MPCV or DSH, then lower to $55.2 \mathrm{kPa}$ (8 psia) for surface ops.

It should be noted that there is a newly-formed ad hoc team re-addressing the issue of atmosphere pressure and \% $\mathrm{O}_{2}$, led by the former EAWG leadership with membership representing materials, fire safety, ECLSS, EVA, health and medical, and the Human Exploration Architecture Team (HAT). It is too soon to determine if the recommendations from this effort will change the previous recommendations, but it is a more thorough investigation than was able to be conducted during the one-day workshop last summer.

\section{Commonality Findings}

The workshop participants identified many areas of potential ECLSS commonality across the exploration architecture elements, and with heritage Shuttle and ISS hardware. Long-duration vehicles such as the Deep Space Hab or surface habs can use ISS ECLSS as a point of departure (POD), with improvements consistent with those recommended in the ECLSS development roadmap ${ }^{2}$. The MPCV ECLSS will generally have applicability as a POD to the MMSEV, SEV, and Lander, or any short-duration crewed vehicle. Specific results are discussed in the following sections, but the graphic in Figure 2 depicts how many ECLSS functions were considered to have strong (green), moderate (yellow), or limited (red) potential for commonality across multiple elements. In summary, of the 36 ECLSS functions analyzed, 16 were considered to have strong potential for commonality across multiple vehicles, including also with heritage Shuttle and ISS hardware; 13 were considered to have some commonality 
potential, and 7 were considered to have limited commonality potential due to unique requirements for exploration or limited heritage hardware.

It is important to mention the discussion relative to factors that will tend to pull in the opposite direction of commonality, as we progress toward exploration element designs. Maintaining vendor supply chains for common hardware production when there will be potentially many years between design and development of each exploration element will be a significant challenge. Parts obsolescence is also expected to be a related issue. It is generally more advantageous if NASA has more than one healthy supplier for spacecraft parts and vendor competition to keep costs down. A common part approach limits vendor competition and may pull against affordability. Finally, since one of the chief goals for exploration is a "highly reliable ECLSS", fault tolerance approaches may favor dissimilar redundancy in some areas instead of common parts across the architecture. These approaches will need to be traded to determine the best combination of affordability vs reliability.

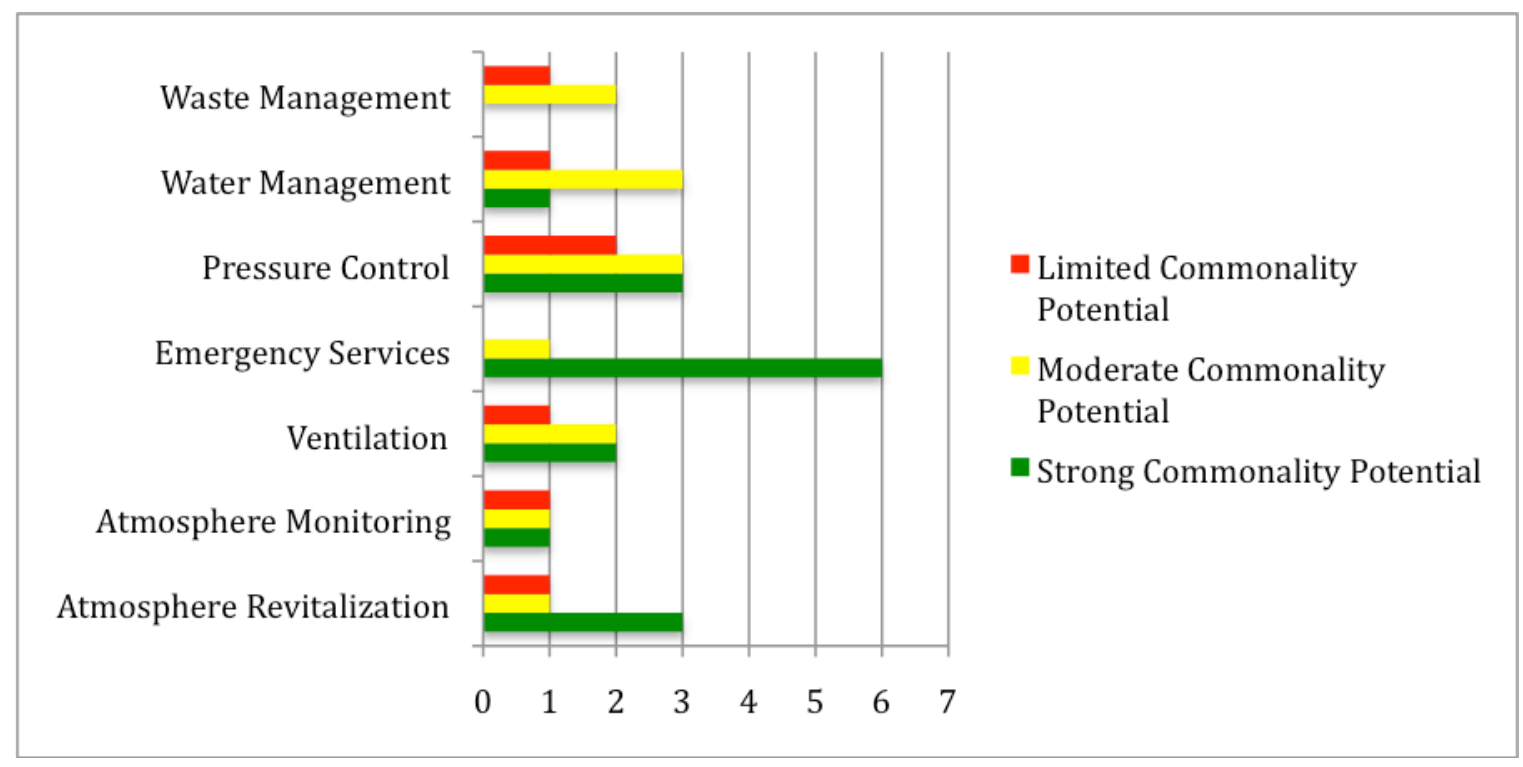

Figure 2. Summary of Commonality Results by Major ECLSS Function

\section{A. Atmosphere Conditioning (Revitalization)}

- (Strong) The pressure swing carbon dioxide $\left(\mathrm{CO}_{2}\right)$ adsorption beds are strong candidates for commonality across all architecture elements, whether they are amine or zeolite-based. Open-loop applications (MPCV, SEV, MMSEV, Lander) can potentially use a common bed "core" for $\mathrm{CO}_{2}$ removal. It may even trade for a PLSS-sized bed to be utilized as a common core, with multiple beds manifolded together depending on crew size. Different vehicles may have different needs for humidity water savings, which can be accomplished using the common core bed with an upstream water-save component (membrane or desiccant). Closed-loop applications (DSH, Surface Hab) can use ISS heritage technology, improved by common core bed with a more robust sorbent material to solve dusting problems, and possible improvements to front end water save and downstream $\mathrm{CO}_{2}$ compressor functions.

- (Strong) Condensing heat exchangers and spin separators for cabin humidity control and condensate collection can utilize ISS heritage technology. Improvements to hydrophilic coating robustness are desirable but may not be mandatory for the mission durations planned.

- (Strong) Trace contaminant control concepts are currently utilizing SoA sorbents and catalytic oxidation technology from Shuttle and ISS. Potential exists for improved performance and reduced weight through use of advanced sorbents, which could/should be common across the exploration architecture.

- (Moderate) Atmosphere Revitalization Subsystem (ARS) fans can use common technology; however, flow/delta pressure design points will likely be too different between vehicle applications (whether there is a need for a suit loop, different vehicle volume) to use one common fan. At a minimum, the SEV and MMSEV can be common, and MPCV and Lander can be common. The DSH and Surface Hab will likely be similar to ISS. Quiet fan technology should be applied across all applications to the extent possible. 
- (Limited) Resource recovery from $\mathrm{CO}_{2}\left(\mathrm{CO}_{2}\right.$ reduction) is only foreseen for long-duration vehicles such as the DSH and Surface Hab, but can at a minimum utilize the ISS Sabatier technology. The need for additional oxygen loop closure will depend on mission trades.

\section{B. Atmosphere Monitoring}

- (Strong) For major atmosphere constituents $\left(\mathrm{CO}_{2}, \mathrm{O}_{2}, \mathrm{~N}_{2}, \mathrm{H}_{2} \mathrm{O}, \mathrm{CH}_{4}\right)$, it was recommended that all vehicles use the same instrument. An improved mass spectrometer is being developed for the MPCV, and ISS is also interested in replacing its SoA Major Constituent Analyzer (MCA). Potential cost sharing discussions between programs are underway. One exception to this approach may be for the SEV, MMSEV, and Lander which may consider an additional dissimilar redundancy if an EVA operation contaminates the baseline sensor. Finally, the DSH and Surface Hab can be common with MPCV, but may require solution for recalibration due to longer active mission durations.

- (Moderate) Short duration vehicles (MPCV, SEV, MMSEV, Lander) are not expected to require on-board trace contaminant monitoring, while long duration vehicles such as the DSH and Surface Hab likely will require this function. While several candidate instruments have been demonstrated on the ISS, there is currently no baselined capability and other candidates are currently under development.

- (Limited) The MPCV, MMSEV will likely not require an airborne microbial monitoring capability. Surface elements such as the SEV, Lander, and Surface Habs will possibly require this capability to ensure planetary protection requirements are being met (no contamination of planetary surfaces). The need for airborne microbial monitoring for a microgravity Deep Space Hab should be evaluated. In all cases, the technology trade space is open as there is currently no SoA capability.

\section{Atmosphere Circulation}

- (Moderate) Cabin ventilation fans have some potential for commonality across elements. The MPCV fan will likely be scaled from heritage fans, and the SEV, MMSEV, and Lander can be common with MPCV due to similar cabin volumes. The DSH and Surface Hab would have the potential to use either heritage ISS or MPCV fans depending on cabin volume and flowrate requirements. It was recommended that all solutions adopt quiet fan technology if available and practical.

- (Strong) For cabin air particulate and microbial control, common use of HEPA filters across all vehicles was recommended, based on heritage technology.

- (Strong) For planetary surface dust control, common use of HEPA filters is possible, augmented by advanced filtration technologies for elements in contact with surfaces.

- (Moderate) Cabin temperature control approaches will vary somewhat between elements. The MPCV is planning a condensing, but "non-slurping" cabin heat exchanger that holds condensate during high metabolic load periods then re-evaporates. The technology is based on ISS heritage. The approach currently envisioned for the SEV, Lander, and Surface Hab will employ a condensing heat exchanger and gravity-based separator to recover the condensate for surface habitat processing and recovery. Microgravity vehicles such as the MMSEV and DSH will employ a traditional condensing heat exchanger and spin separator for condensate collection and recovery.

- (Limited) One ventilation feature that is unique to the MPCV is the post-landing ventilation fan, which is used to bring in fresh, outside air for the crew while waiting on rescue. While heritage designs can be leveraged, the flowrate, head rise, and ability to operate after exposure to salt water makes this a unique fan.

\section{Emergency Services}

- (Strong) The smoke detector required for all elements can be common. The detector planned for the MPCV leverages a commercial airline sensor adapted for spacecraft requirements. All other vehicles can be common with MPCV. If further improvements to technology are made, such as detection of CO in addition to smoke particles, or incipient fire detection, this technology could be utilized across all vehicles as well.

- (Moderate) A surface dust detector may be required for all vehicles except the MPCV that could come in contact with planetary surfaces or be exposed to elements that have returned from surfaces. The trade space for this technology is open as there is currently no SoA sensor.

- (Strong) For portable fire suppression, there is a need to replace the current SoA suppressant, which has been Halon for Shuttle and $\mathrm{CO}_{2}$ for the ISS. Halon has become difficult to obtain due to Environmental Protection Agency (EPA) restrictions, and is also prohibited for use on spacecraft where it may become exposed to high temperature catalytic oxidation in trace contaminant control systems, as it breaks down into highly toxic compounds. $\mathrm{CO}_{2}$ will asphyxiate the crew at the concentration necessary to suppress a fire in a small cabin 
volume. Currently, the ISS is investing in the development of a water mist replacement to its $\mathrm{CO}_{2}$ Portable Fire Extinguisher (PFE). The MPCV plans to leverage this development for a similar water mist extinguisher. All other vehicles can and should use the same PFE, particularly to avoid crew training on different devices across different elements. One exception is that the DSH and Surface Hab elements may also require an automatic inert gas flooding-type system for equipment bays in addition to portable fire suppression, especially with long dormant periods.

- (Strong) All vehicles will require a contingency breathing mask for the crew in case of a fire or cabin contamination. The ISS is currently investing in the development of a gold oxide cartridge filter mask to replace its current SoA $\mathrm{O}_{2}$ mask. In a small cabin in particular, the overflow from an $\mathrm{O}_{2}$ mask will enrich the cabin $\mathrm{O}_{2}$ concentration to unacceptable levels, particularly if the crew is fighting a fire. The MPCV plans to leverage the new ISS mask directly, and all other vehicles plan to be common with MPCV/ISS mask.

- (Strong) While cabin depress/repress can be utilized to restore a cabin atmosphere following a fire or contamination event, this operation is risky for the crew and utilizes significant gas consumables. A better solution is to employ some sort of "smoke eater" device. The MPCV currently has nothing baselined but is looking into the possibility of a catalyst-filled replacement for the HEPA filter that could be deployed following an emergency while the crew is still on masks. All other vehicles could utilize a similar if not identical device. The SEV and MMSEV will also have PLSS's as a backup in case of cabin contamination.

- (Strong) Some elements such as the MPCV will require the capability to detect hazardous fluids from cooling systems or propellant, such as ammonia or hydrazine. The MPCV is investigating the adaptation of a handheld commercial sensor such as has been used on the ISS and Shuttle, although other technologies are also being considered. The MMSEV and DSH may utilize the same device as the MPCV, but it is not anticipated that the SEV or Lander will need anything due to current propulsion and cooling technology selections.

- (Strong) All vehicles will require a post-fire "combusted gas" sensor $(\mathrm{HCl}, \mathrm{HCN}, \mathrm{CO})$. The ISS heritage Compound Specific Analyzer-Combustion Products (CSA-CP) is a near-term candidate for the first MPCV missions; however, exposure to vacuum and parts obsolescence may require an upgrade or replacement to be adequate for future vehicles. In any case, all vehicles should be able to use the same common device.

\section{E. Atmosphere Pressure Management}

- (Some) The MPCV and Lander are two of the exploration elements currently envisioned to contain a "suit loop" in which the crew in pressure suits are connected through umbilicals to a closed loop which controls their pressure and atmosphere constituents. The pressure regulator for this loop has unique requirements; however, the MPCV is leveraging off the suit PLSS regulator to the extent possible. The Lander can be common with MPCV.

- (Strong) For cabin pressure control, The MPCV is currently attempting to utilize as many common propulsion components as possible; however, oxygen compatibility drives unique materials for some of those components. The MPCV must also size its $\mathrm{O}_{2}$ introduction to feed a cabin leak in an emergency. The SEV, MMSEV, Lander architecture teams are trading the use of suit PLSS regulators versus a common MPCV system. The DSH and Surface Hab could either be ISS- or MPCV-like depending on cabin volume and flowrate requirements.

- (Strong) For cabin pressure equalization, all vehicles can likely be common with the MPCV's powered and manual valves. The Habs may need resizing due to larger vehicle volumes.

- (Strong) For cabin positive pressure relief, the MPCV is using a heritage ISS valve for its first test flight. While this same valve size and function may likely work for subsequent flights, there is not enough remaining ISS inventory to accommodate MPCV needs and the electronics may not withstand MPCV loads. However, a new Positive Pressure Relief Valve (PPRV) designed for MPCV can most likely be used across all other exploration elements.

- (Limited) The function of negative pressure relief is unique to the MPCV, as no other elements will require return to Earth atmosphere. Due to the requirement to seal after a water landing, the MPCV Negative Pressure Relief Valve (NPRV) needs to be a new design; heritage ISS NPRV's will not meet this requirement.

- (Moderate) Nitrogen gas pressurized storage may have some commonality potential across elements. The MPCV is using $34,474 \mathrm{kPa}(5000 \mathrm{psi})$ tanks. All other elements are currently sizing based on a 20,684 $\mathrm{kPa}$ (3000 psi) assumption, but could utilize the MPCV tanks if trade favorably.

- (Moderate) Similar to nitrogen, oxygen gas storage has some commonality potential. The MPCV is also using $34,474 \mathrm{kPa}$ (5000 psi) tanks for oxygen, but currently has no plans for these to be rechargeable. The 
SEV, MMSEV, and Lander require a recharge capability for EVA replenishment, and plan a pressure of $24,821 \mathrm{kPa}(3600 \mathrm{psi})$ for this function. The DSH and surface hab may use either high pressure tanks or cryogenic technology. For oxygen recharge, the ISS is sponsoring a study for a device which would dry and compress the output of the Oxygen Generation Assembly for EVA use. It is hoped that the resulting solution will also meet requirements for Exploration DRMs.

- (Limited) Oxygen generation is currently a unique function planned only for the longer-duration elements: DSH and surface habs. This function will not likely be required, nor will it fit, on the MPCV, SEV, MMSEV, or Lander. The POD for oxygen generation is considered to be the ISS Oxygen Generation Assembly (OGA), with resolution of reliability issues through upgrades and flight demonstration. Alternate technologies are at a considerably lower technology readiness level and would require significant investment to be considered.

\section{F. Water Management}

- (Moderate) For potable water storage, all elements are currently planning to use metal bellows tanks. Vehicles designed for a gravity environment plan to use metal tanks (no bellows required). Some heritage ISS tank designs may work for all elements. The DSH may also trade storage options with radiation protection.

- (Strong) There was strong agreement among the community that all elements should design for the same microbial control biocide, and there was general consensus that silver is the preferred biocide. Issues with long term storage and depletion of silver in metal tanks over time must be resolved, and a delivery and/or recharge method must be developed.

- (Moderate) No water processing capability is currently planned for the shorter-duration vehicles (MPCV, SEV, MMSEV, Landers). The DSH and Surface Hab concepts currently consider the ISS Water Processor Assembly (WPA) and Urine Processor Assembly (UPA) as the POD, with the desire to improve upon its expendable resupply rate, and percent of water recovered from urine depending on mission duration. Issues with the UPA reliability discovered during initial ISS operations have largely been resolved and may or may not be improved further by a change in technology currently under development. The chief issue remaining is the resolution of calcium precipitation, which is being addressed by the ISS and Advanced Exploration Systems (AES) Programs.

- (Moderate) For urine collection and pretreatment, the microgravity elements are planning to utilize a urinal/spin separator common with the MPCV, which is Shuttle-derived. The DSH will deliver urine for processing instead of venting overboard. Gravity-based elements can use a simpler, gravity-based collection tank. The heritage pretreat formula (oxone/sulfuric acid) is currently planned for the MPCV, SEV, MMSEV, and Lander concepts. The DSH and Surface Hab, which will employ urine processing, desire an alternate pretreat with lower toxicity and no precipitation versus either the current Russian ISS pretreat or US oxone/sulfuric acid formula. If successfully developed, this alternate pretreat could be employed as a block upgrade across all elements.

- (Limited) Short duration vehicles are not expected to require on-board water quality monitoring (chemical or microbial). Samples can be drawn for analysis in the DSH or Surface Hab as needed. The DSH and Surface $\mathrm{Hab}$ (or long duration vehicles) are recommended to have improved capability over the ISS SOA, which is offline sample analysis. Current environmental monitoring roadmap efforts are attempting to address specific gaps.

\section{G. Solid Waste Management}

- (Moderate) For fecal collection and storage, the MPCV is currently planning to use a commode derived from the Shuttle EDO design, which employs microgravity features. Development of a more compact commode for commercial crew vehicles is being studied and may very well serve the needs for NASA's exploration elements. Other microgravity vehicles (MMSEV, DSH) should use the same common commode. Gravitybased vehicles (SEV, Lander, Surface Hab) can take advantage of a more simple "camper style" design. The Hab vehicles may also need to integrate fecal collection with solid waste processing (depending on trades) and also consider long term storage/planetary protection.

- (Limited) Fecal processing (drying, water recovery) is not foreseen for any vehicle except potentially the long-duration habitats depending on trades. If implemented, it is highly desirable (if not mandatory) that the processing function be accomplished without the need for the crew to manually move the fecal material from the collection container to the processor. 
- (Moderate) For all other trash collection and processing, all vehicles can utilize common assorted trash bags. The long-duration habitats are considering compaction and dewatering for long-term stabilization and resource recovery, and possible repurposing of the resulting product for radiation protection.

\section{Activities Subsequent to Workshop}

There has been a great deal of activity over the past year relative to NASA's and the International community's planning for future Exploration missions. These activities have included further definition and refinement of exploration strategies and roadmaps, potential design reference missions, architectures, and trades, and assessments of the capabilities needed to accomplish these plans. The ECLSS community has been actively involved in supporting these efforts, and has been a pathfinder in developing its own capability development roadmap. This activity and results are described in much more detail in reference 2 ; however, the resulting recommendations have been very positively received throughout the HEOMD organization and are being used to inform technology investment decisions going forward. In addition, the ECLSS community has begun to share results and engage both the US industry and international communities in an effort to partner together toward filling the gaps needed for exploration. Cooperative efforts including demonstrations using ISS as a testbed are in discussion.

Through these activities, there has so far been little change to the initial recommendations relative to commonality discussed last summer and presented here. Architecture studies to date have used these recommendations as points of departure in parametric analyses. As these studies mature, as well as the results of the new EAWG assessment, we may likely need to revisit recommendations for commonality and recognize it will be an ongoing thought process.

\section{Conclusion}

This paper has addressed findings from a NASA ECLSS community-wide study on commonality across potential Exploration architectures, including considerations relative to the selection of atmosphere pressure and oxygen design points. As presented, there is an overall strong potential to use common ECLSS components across architecture elements, including heritage ISS and Shuttle components as well. The benefits of using common components must be weighed against the potential disadvantages of a need for dissimilar redundancy, promotion of competition, and parts obsolescence. As we go forward as an international community challenged by budget constraints, these advantages and disadvantages will need to be balanced as architectures are defined and matured and technology and component selections are made.

\section{Acknowledgments}

This effort was enabled through broad ECLSS community participation and support. Though it is impractical to name each participant, the authors wish to specifically acknowledge and thank the following individuals for specific contributions to this work: Jordan Metcalf, Bob Bagdigian, Hank Rotter, and the rest of the Thermal/ECLSS Steering Committee for sponsoring and supporting this and the subsequent roadmapping efforts, Mike Pedley for his expertise in materials flammability, Imelda Stambaugh for providing insight into current ECLSS architecture trades, and John Lewis for Orion ECLSS support.

\section{References}

1"Recommendations for Exploration Spacecraft Internal Atmospheres: The Final Report of the NASA Exploration Atmospheres Working Group", NASA/TP-2010-216134, NASA Exploration Atmospheres Working Group, NASA Johnson Space Center, October 2010.

${ }^{2}$ Metcalf, J., Bagdigian, R., Carrasquillo, R., and Peterson, L, "National Aeronautics and Space Administration (NASA) Environmental Control and Life Support (ECLS) Integrated Roadmap Development", AIAA 1285902, 42 ${ }^{\text {nd }}$ International Conference on Environmental Systems, San Diego, CA, July 2012. 